\title{
Ética en el uso de las imágenes clínicas en cirugía
}

\section{Ethics in the use of clinical images in surgery}

\author{
Lilian Torregrosa A. D
}

MD, FACS, especialista en Cirugía de Seno y Tejidos Blandos y magíster en Bioética; profesora asociada de Cirugía, Directora Departamento de Cirugía y Especialidades, Facultad de Medicina, Pontificia Universidad Javeriana, Hospital Universitario San Ignacio, Bogotá, D.C., Colombia.

En los últimos años, el uso de plataformas y redes sociales se ha convertido en una realidad para muchos millones de personas en todo el mundo, a la cual los médicos no podíamos ser ajenos. Por el contrario, la profesión médica ha reconocido las ventajas que esta comunicación ofrece y ha incorporado sus herramientas a las prácticas rutinarias, lo que permite recopilar, compartir y difundir información de salud, facilitar la comunicación con otros profesionales, llevar a cabo investigación, desarrollar estrategias de salud pública y de educación, socializar o conectar con amigos y familiares, e incluso lograr la promoción profesional.

En el ejercicio clínico son innegables las ventajas que ofrece el compartir velozmente información científica, intercambiar opiniones clínicas entre equipos tratantes y colegas, o solicitar apoyo profesional a través de canales virtuales.
En la mayoría de estos escenarios de interacción se hace evidente que "una imagen vale más que mil palabras", por lo que la difusión de videos y fotografías se ha convertido en una práctica cada vez más diseminada, que trasciende el escenario clínico, llegando al terreno de la educación médica, la investigación y la academia, donde estas imágenes adquieren también un significativo valor para el avance de la profesión y el beneficio de la sociedad.

Si bien muchos profesionales de la salud utilizan las redes sociales sin ninguna dificultad, los cada vez más numerosos ejemplos de comportamiento no profesional en línea que han llevado a procesos disciplinarios y sanciones, han generado preocupación de que los médicos, residentes y estudiantes de medicina puedan exponerse a riesgos no anticipados debido a la forma en que usan estas aplicaciones, pues de todos los

Palabras clave: ética médica; cirugía general; red social; medios de comunicación sociales; confidencialidad; privacidad.

Keywords: ethics, medical; general surgery; social networking; social media; confidentiality; privacy.

Fecha de recibido: 03/09/2020 - Fecha de aceptación: 05/09/2020

Correspondencia: Lilian Torregrosa A, Carrera 7 No 40-62 Oficina 718, Servicio de Cirugía, Hospital San Ignacio, Bogotá, D.C.,

Colombia. Teléfono: (57-1) 5946161 Ext 2240

Correo electrónico: Iilian.torregrosa@javeriana.edu.co, Itorregrosa@husi.org.co

Citar como: Torregrosa Lilian. Ética en el uso de las imágenes clínicas en cirugía. Rev Colomb Cir. 2020;35:547-9.

https://doi.org/10.30944/20117582.765

Este es un artículo de acceso abierto bajo una Licencia Creative Commons - BY-NC-ND https://creativecommons.org/licenses/by-nc-nd/4.0/deed.es 
miembros de la profesión se espera un comportamiento "on-line" ajustado a las mismas normas que rigen el profesionalismo médico fuera del entorno virtual.

Uno de los aspectos más problemáticos lo representa el uso de las imágenes que involucran pacientes y escenarios de atención sanitaria, conocidas como "imágenes clínicas". Si bien es una realidad que, tanto fotografías como videos, se han convertido en un componente esencial e imprescindible en muchas áreas de la medicina y la cirugía gracias a la evolución de la tecnología digital, y su uso generalizado constituye hoy una herramienta fundamental para el manejo cotidiano de los pacientes, estos indudables beneficios no están libres de problemas éticos, legales y sociales, relacionados con el uso y almacenamiento de la información que contienen, la cual es confidencial y privada.

Frente a esta realidad se hace necesario establecer un equilibrio entre las medidas de protección y el acceso a la información contenida en estas imágenes, que permita su uso asistencial, científico y académico, bajo unas condiciones definidas que aseguren que esta información confidencial estará protegida durante su almacenamiento y posterior difusión. No hay que olvidar que las imágenes clínicas son parte de los datos de salud de una persona, y como tal, hacen parte de la información más sensible que un individuo posee.

Las redes sociales más utilizadas por los médicos actualmente son Facebook, Twitter, Youtube y blogs. Su advenimiento ha generado la necesidad adicional de tener unos lineamientos éticos claros con respecto a lo que se considera un uso profesional de estas "realidades" que, si bien son naturales para las generaciones de nativos digitales y muy atractivas para toda la comunidad médica, muchas veces ofrecen riesgosos espejismos de finitud y privacidad, que no están libres de llevar a potenciales faltas al profesionalismo médico, e incluso problemas médico-legales. Una razón más por la cual hoy se hace un llamado a que los médicos consideren este nuevo escenario de interacción social como un espacio donde aplican las mismas responsabilidades y principios del profesionalismo médico, el llamado "profesionalismo on-line".

A nivel mundial, numerosas organizaciones y asociaciones médicas se han pronunciado respecto a este nuevo reto de la medicina moderna, especialmente aquellas áreas donde el uso de las imágenes como parte del ejercicio adquiere un mayor valor, como es el caso de la cirugía. Se han establecido unos parámetros y orientaciones basadas en los sólidos principios éticos que subyacen a esta práctica y que se pueden resumir en las recomendaciones que plantearé a continuación:

- Solicitar siempre la autorización para el registro y uso de la imagen de un paciente. Esta práctica debe anteceder a cualquier publicación (dentro y fuera de las redes sociales), como muestra del respeto por la autonomía de cada individuo para aceptar o rechazar los cursos de acción clínica que se le proponen, incluyendo el registro de sus imágenes. Es importante recordar que el respeto a la dignidad de los pacientes entraña el deber de someter, bajo adecuadas provisiones de información e independencia, toda alternativa de diagnóstico y tratamiento a su consentimiento.

- Considerar en todos los casos, y antes de llevar a cabo el registro de la imagen clínica, que existan razones justificadas para hacerlo (ya sea por su utilidad en la atención del mismo paciente, o buscando una intención secundaria de orden académico, investigativo o incluso publicitario).

- Preservar la confidencialidad de la imagen y los datos médicos contenidos en ella. Mantener esta confidencialidad es un deber médico, así como salvagurardar la privacidad del paciente, su dignidad, integridad y condiciones de vulnerabilidad.

- Buscar el anonimato de las imágenes siempre que sea posible, teniendo en cuenta que este 
proceso de des-identificación no sólo tiene que ver con imposibilitar el reconocimiento facial, sino que hace referencia también a eliminar toda la información que permita la identificación del paciente en la imagen y sus textos anexos (tatuajes, joyería, marcas personales, datos de fecha, lugar, entre otros).

- Evitar sucumbir a la necesidad de compartirlo todo sin una justificación clara o un beneficio evidente para el paciente o la profesión, a la inmediatez y la velocidad que exigen las comunicaciones digitales y que fácilmente pueden llevar a errores no intencionales, por imprudencia o falta de previsión, y comprometer la imagen profesional del médico.

- Considerar que compartir, almacenar, transmitir y manejar de manera segura la información clínica, incluyendo las imágenes, es una medida que protege a los médicos y a los pacientes por igual.

Constituye un imperativo ético examinar los desafíos relacionados con el uso, cada vez mayor, de estas formas de comunicación virtual por parte de médicos, estudiantes de medicina y pacientes, con el fin de establecer un marco que proteja sus respectivos intereses y mantenga la confianza en la privacidad del acto médico, así como la reputación de la medicina y los altos estándares profesionales y éticos que la caracterizan.
Con la orientación correcta, el uso de las imágenes clínicas seguirá siendo un complemento de extrema utilidad para la atención de los pacientes y el desarrollo de la profesión médica, y en el futuro seguramente traerá nuevas e innumerables posibilidades de intercambio inmediato $\mathrm{y}$ remoto, aun imposibles de avizorar, pero ciertamente retadoras para la ética y el profesionalismo médico.

\section{Lecturas recomendadas}

American Medical Association. Professional guidelines for social media use: A starting point. AMA J Ethics. 2015;I7:44I-7.

https://doi.org/IO.IOoI/journalofethics. 2015.I7.5.nlitI -I505

Logghe HJ, Boeck MA, Gusani NJ, Hardaway JC, Hughes KA, Mouawad NJ, et al. Best practices for surgeons' social media use: Statement of the resident and associate society of the American College of Surgeons. J Am Coll Surg. 2018;226:317-27.

https://doi.org/IO.IoI6/j.jamcollsurg.2017.II.022

Torregrosa-Almonacid L, Gempeler-Rueda FE, editores. Ética en el uso de las imágenes clínicas. Bogotá: Editorial Pontificia Universidad Javeriana; 2020. ISBN 97895878I4606.

Bennett KG, Bonawitz SC, Vercler CJ. Guidelines for the ethical publication of facial photographs and review of the literature. Cleft Palate Craniofac J. 2019;56:7-I4. https://doi.org/IO.II77/I0556656I8774026

Bennett KG, Berlin NL, MacEachern MP, Buchman SR, Preminger BA, Vercler CJ. The ethical and professional use of social media in surgery: A systematic review of the literature. Plast Reconstr Surg. 20I8;142:388e-398e. https://doi.org/I0.I097/PRS.0000000000004692 